reported Adherence, but only 42 (50\%) had High Refills. Minorities had lower rates compared to Caucasians for both High Self-reported Adherence $(55 \%$ vs $81 \%, p=0.02)$ and High Refills ( $40 \%$ vs. $68 \%, \mathrm{p}=0.01)$. Among 52 taking disease modifying agents (DMARDs) including methotrexate, leflunomide, azathioprine, and mycophenolate, High Refill rate was only $46 \%$, and the difference between minorities and Caucasians was even larger $(35 \%$ vs. $73 \%, p=0.01)$. In this group, the Low Refill group had higher SLEDAI (4 vs 2, $\mathrm{p}=0.02$ ), PGA2 ( 1 vs $0, \mathrm{p}=0.04$ ), and a trend for living with children $(41 \%$ vs. $17 \%, \mathrm{p}=0.07)$ compared to those with High Refill rates. There were no statistically significant differences between the DMARD High and Low Refill groups in terms of positive and negative affect, self-efficacy, patient-provider interactions, patient self-reported outcomes, and other clinical factors.

Conclusions Significant racial disparities exist in lupus medication adherence, and the gap is even more substantial for patients taking DMARDs, medications crucial for the treatment of more severe lupus manifestations. This gap likely contributes to the known racial disparities in SLE outcomes. We did not discover potential modifiable factors in this small sample. Qualitative studies are needed to better understand this racial gap and to develop interventions that address racial disparities in SLE.

Funding Source(s): 5U54MD012530-02

\section{IFN-KINOID IN SYSTEMIC LUPUS ERYTHEMATOSUS (SLE): RESULTS FROM A PHASE 2B, RANDOMIZED, PLACEBO-CONTROLLED STUDY}

${ }^{1}$ Frédéric Houssiau*, ${ }^{2}$ Aikaterini Thanou, ${ }^{3}$ Minodora Mazur, ${ }^{4}$ Edgar Ramiterre, ${ }^{5}$ Danny Alexis Gomez Mora, ${ }^{6}$ Maria Misterska-skora, ${ }^{7}$ Risto Perich Campos, ${ }^{8}$ Svetlana Anatolyevna Smakotina, ${ }^{9}$ Sergio Cerpa Cruz, ${ }^{10}$ Bassem Louzir, ${ }^{11}$ Therese Camille, ${ }^{12}$ Michael Tee. ${ }^{1}$ Service de Rhumatologie, Cliniques universitaires Saint-Luc, Brussels and Pôle de Pathologies Rhumatismales Inflammatoires et Systémiques, Université catholique de Louvain; ${ }^{2}$ Research Affiliate Arthritis and Clinical Immunology Research Program Oklahoma Medical Research Foundation; ${ }^{3}$ University Professor at State Medical and Pharmaceutical University; ${ }^{4}$ Section of Rheumatology, Department of Internal Medicine, Southern Philippines Medical Center JP Laurel Ave, Davao City Philippines; ${ }^{5}$ Rheumatologist from UNIVERSIDAD NACIONAL DE COLOMBIA Healthy Medical Center Kra 4 \# 7-39 Zipaquira; ${ }^{6}$ Medical Center Oporów Solskiego 4a/1 52-416 Wrocaw; ' Rheumatology Department, Hospital Nacional Guillermo Almenara Irigoyen. EsSalud. Lima- Perú. Universidad Nacional Mayor de San Marcos; ${ }^{8}$ Doctor of medical sciences, professor of Kemerovo State Medical University; ${ }^{9}$ Attending Physician and Associated Clinical Professor Medicine/Rheumatology Department Hospital Civil de Guadalajara; ${ }^{10}$ Head of Department of Internal Medicine Military hospital of Tunis 1008 Tunis; ${ }^{11}$ Neovacs; ${ }^{12}$ Vice Chancellor Medical Center Manila, Rheumatology Department UP Manila College of Medicine and ManilaMed

\subsection{6/lupus-2019-Ism.198}

Background The immunotherapeutic vaccine Interferon-kinoid (IFN-K) consists of a heterocomplex of inactivated recombinant human IFN-2b coupled to a T-helper carrier protein, Keyhole Limpet Haemocyanin. A phase I/IIa was published. Here, we report the results of a 36 week (w) phase $2 b$, randomized, double-blind, placebo-controlled (PBO), multi-center study assessing the efficacy and safety of IFN-K in patients with active SLE on standard of care therapy.

\begin{tabular}{llll} 
Abstract 198 Table 1 & & \\
\hline & IFN-K & Placebo & p value \\
\hline IFN gene signature reduction & $-31.3 \%$ & $-0.4 \%$ & $<0.0001$ \\
Modified BICLA & $35(41.2 \%)$ & $29(34.5 \%)$ & 0.33 \\
SRI(4) & $57(67.9 \%)$ & $54(65.1 \%)$ & 0.62 \\
SRI(4) with CS $\leq 5 \mathrm{mg} / \mathrm{d}$ & $43(54.4 \%)$ & $30(39 \%)$ & 0.07 \\
SRI(4) with CS $\leq 5 \mathrm{mg} / \mathrm{d}$ & $40(55.6 \%)$ & $30(39.0 \%)$ & 0.04 \\
(IFN-K subgroup with neutralizing Abs) & & & \\
SRI(4) with CS $\leq 7.5 \mathrm{mg} / \mathrm{d}$ & $46(58.2 \%)$ & $33(42.9 \%)$ & 0.07 \\
SRI(4) with CS $\leq 7.5 \mathrm{mg} / \mathrm{d}$ & $43(59.7 \%)$ & $33(42.9 \%)$ & 0.04 \\
(IFN-K subgroup with neutralizing Abs) & & & \\
LLDAS & $45(52.9 \%)$ & $25(29.8 \%)$ & 0.002 \\
Mean CS dose * & $5.4 \mathrm{mg} / \mathrm{d}$ & $7.1 \mathrm{mg} / \mathrm{d}$ & 0.009 \\
\hline
\end{tabular}

*The mean daily CS dose was lower in the IFN-K group from w28 onwards.

Methods SLE patients (4 ACR criteria) with moderate to severe disease activity (SLEDAI 2K 6 and 1 BILAG A and/or 2 BILAG B scores); positive IFN gene signature; and ANA and/or anti-dsDNA, were randomized (1:1) to 5 IM injections of IFN-K or PBO at days $0,7,28$, and months 3 and 6. Coprimary objectives at $\mathrm{w} 36$ were neutralization of IFN gene signature and BICLA response modified by mandatory corticosteroid (CS) tapering ( $5 \mathrm{mg} / \mathrm{d}$ prednisolone equivalent) by w24 with no increase to w36. Secondary objectives at w36 were SRI(4) and SRI(4) with CS tapering (5 mg or $7.5 \mathrm{mg} / \mathrm{d}$ prednisolone equivalent) by w36, Lupus Low Disease Activity State (LLDAS), safety and immunogenicity.

Results Among 185 patients randomized, 91 and 93 were respectively treated with IFN-K and $\mathrm{PBO}$, and 85 (92.4\%) and $84(90.3 \%)$ completed the study. Seventy-two of 79 (91.1\%) IFN-K treated patients (Per Protocol Set) developed anti-IFN neutralizing antibodies (Abs). Primary and secondary outcome measures at w36 are detailed in the Table:

IFN-K was well tolerated, with similar rates of treatmentemergent adverse events (TEAEs $82.4 \%$ vs $76.3 \%$ ) and TEAEs leading to study drug discontinuation $(4.4 \%$ vs. $4.3 \%)$ in the IFN-K and PBO groups, respectively. Serious adverse events (SAEs) were more common on $\mathrm{PBO}$ vs IFN-K $(12.9 \%$ vs $6.6 \%)$. Cancer $(n=4)$ and lupus nephritis $(n=2)$ were reported in the PBO group and there was one severe infection in the IFN-K group. One death occurred in each group.

Conclusions IFN-K induced neutralizing anti-IFN Abs in $91.1 \%$ of treated patients and significantly reduced IFN gene signature. Modified BICLA at w36 did not differ between IFN-K and PBO. Trends on SRI (4) with steroid tapering at w36 favored IFN-K, and became significant when patients exhibiting neutralizing Abs were included in the exploratory analysis. Furthermore achieving a Lupus Low Disease Activity State discriminated the two groups at w36, in favor of IFN-K. A significant CS sparing effect of IFN-K was observed from w28 onwards. The safety profile of IFN-K was acceptable. Results merit further evaluation in phase 3 studies.

Funding Source(s): The study was funded by Neovacs. 